\title{
MONITORING OF AGRICULTURAL DROUGHT USING FORTNIGHTLY VARIATION OF VEGETATION CONDITION INDEX (VCI) FOR THE STATE OF TAMIL NADU, INDIA
}

\author{
N. Vaani ${ }^{1 *}$, P.Porchelvan ${ }^{2}$ \\ ${ }^{1}$ Centre for Disaster Mitigation and Management (CDMM), Vellore Institute of Technology (VIT), Vellore \\ -632014, Tamil Nadu, India - nvaani@vit.ac.in \\ ${ }^{2}$ School of Civil and Chemical Engineering (SCALE), Vellore Institute of Technology (VIT),Vellore - 632014, Tamil Nadu, India \\ - pporchelvan@vit.ac.in
}

KEYWORDS: Agricultural drought monitoring, Vegetation condition index (VCI), Drought severity map, Geographic Information Systems (GIS), Normalized differenced vegetation index (NDVI).

\begin{abstract}
:
India being an agrarian nation widely depends upon rainfall for its agricultural productivity. The failure of rainfall and hence shortfall of productivity badly affects national economy. With an intricate nature of drought, the planning and management requires rigid monitoring for better understanding. The occurrence of drought and its severity varies in a regional level. The process of monitoring agricultural drought in a regional level requires long term analysis of vegetation. In this present work, the attempt has been carried out to study and monitor the spatial and temporal variation of agricultural drought for the state of Tamilnadu, India which is more prone to drought especially due to monsoon failure or change in monsoon. The long term Normalized differenced vegetation index (NDVI) of Global Inventory Modelling and Mapping Studies (GIMMS) for the period of 20 years (1984-2003) was used to compute the most popular index called vegetation condition index (VCI) to identify the vegetation vigour. The fortnightly variation of VCI during major crop growing period of Kharif season (June to September) was used to monitor the spatiotemporal drought conditions of Tamil Nadu. The results proved that there is wide variation of drought intensity among the districts within the state. The keen observation of fortnightly variation of long term agricultural drought helps finding the onset, period and spatial extent of drought in various districts of the state. The districts which are most often prone to moderate to severe drought conditions during the analysis period were recognized in order to develop various strategies to improve the agricultural productivity in that region. The persistent drought in the state necessitates the government to take appropriate preventive measures to evade drought in future. Based on the severity of the drought level observed from the agricultural drought intensity maps prepared using VCI, the action plans could be prioritized by identifying the high risk zones.
\end{abstract}

\section{INTRODUCTION}

Due to the effects of climate change, the precipitation losses and agricultural drought are more common in recent years in most parts of the world. In the developing country like India where approximately $54.8 \%$ of people are dependent on agriculture, the drought vulnerability is significantly increased by extreme weather events, temperature rise and lower rainfall. This abnormal dry weather consecutively results in a wide range of negative physical impact and socio-economic setback in the country. Those physical impacts include ground water depletion, drying-up of ponds, rivers, lakes, wells and reservoirs, shortage of food grains due to reduction in agricultural productivity. These impacts also lead to socio economic issues in the country like rise of international commodity values, mortgage or sale of productive crop lands to promote real estate business , migration of population from villages to urban centres, increase of insecurity in the minds of people which leads to suicides, social offence, etc. In India, 3,228 farmers committed suicide in 2015 which accounts to an average of 9 suicides/day. The failure of crops due to erratic monsoon onset, duration and severity level is the prime reason for farmers to go on debt and attempt suicide due to their inability to repay the agricultural loan. As the severity of the problem is found to be increasing every year in India, its an urgent need of the hour to take necessary actions to monitor the trend in severity level of drought and be prepared enough to face the crisis situation.
The various types of drought ie., meteorological, hydrological and agricultural drought are all related to each other. When the actual precipitation is considerably less than the normal level (meteorological drought), it leads to obvious depletion of ground water and surface water levels (hydrological drought) which in turn causes drying up of land and severe crop stress (agricultural drought). The precise spatial analysis of meteorological drought severity level requires dense network of rain gauge stations. But the availability of weather data is constricted in many regions whereas spatio temporal analysis of agricultural drought can efficiently be made with the advancement in the fields of satellite remote sensing and Geographic Information Systems (GIS).

One of the most popular vegetation indices, which is commonly used by researchers across the world for monitoring and assessing the agricultural drought is Normalized differenced vegetation index (NDVI). As NDVI is a good indicator of vegetation stress (Anyamba et al.,2001), (Domenikiotis et al.,2004), (Dutta et al.,2013), (Dutta et al.,2015), (Fensholt et al.,2012), ( Jain et al.,2010), (Legess et al.,2014) and (Quiring et al., 2010) it is proved to be efficient in all drought related studies. The radiation principle in the calculation of NDVI uses two different energy bands viz., Near-Infrared (NIR) and red region of visible band(VIS). As the healthy and dense green vegetation strongly reflects NIR radiation, it greatly absorbs visible red radiation of the electromagnetic spectrum. In 
case of unhealthy poor vegetation, the above case is upturned. This particular characteristics best suits to study and analyse the status of vegetation growth in a region using the following rule to estimate NDVI.

$$
\begin{array}{ll}
N D V I & (N I R- \\
= & \frac{V I S)}{(N I R+} \\
& V I S)
\end{array}
$$

The value of NDVI ranges between minimum of -1 and maximum of +1 . If the value goes below 0.1 , it stands for barren rock, sand, water clouds and snow but when values go above 0.7. it signifies dense tropical rainforests ((Fensholt et al.,2012). The current study is attempted to envisage the efficiency of drought monitoring using NDVI based index called vegetation condition index (VCI). The efficiency of remote sensing derived $\mathrm{VCI}$ in assessing agricultural drought were ascertained as the correlation analysis between VCI and major rain fed crops showed correlation coefficient of 0.75 . (Dutta et al.,2015). The assessment of regional drought impacts can be made effectively using VCI. The drought areas are hence well delineated with certain threshold values of NDVI and VCI. It was also proved that these delineation matched well with rainfall anomalies observed from rainfall maps (Liu et al, 1996). VCI also allows to assess the trend in frequency of regional drought. (Liang et al., 2017)

Drought as a creeping phenomena, is hard to understand among all the natural disasters. The drift of drought could not be analysed properly using only the trend in recent years. It also necessitates the long period of analysis to derive conclusion about the changing pattern of agricultural drought. So, the long term analysis of VCI was adopted to monitor the agricultural drought in the state of Tamil Nadu, India . The VCI based fortnightly variation of agricultural drought severity maps were prepared to identify the drought risk zones. The state government authorities may find it useful for understanding the drought risk areas and thereby prioritize their actions while extenuating for the drought period.

\section{STUDY AREA}

The present area of study is Tamil Nadu state which is located in south eastern part of Indian peninsula and is shown in Figure 1. The geographical extent of the state lies between $08^{\circ} 00^{\prime} \mathrm{N}$ to and $13^{\circ} 30^{\prime} \mathrm{N}$ Latitudes and between $76^{\circ} 15^{\prime} \mathrm{E}$ and $80^{\circ} 18^{\prime}$ E Longitudes. The total area of Tamil Nadu extends to $1,30,058 \mathrm{~km}^{2}$ and it stands as the eleventh largest state in India. The adjacent states of Tamilnadu include Andhra Pradesh and Karnataka in North and Kerala on the West. East of the state is bounded by Bay of Bengal and south of the state is covered by Indian Ocean. The eastern side of state is also surrounded by a union territory called Pondicherry.

Tamilnadu is the state in India where rain fed agriculture is the predominant occupation. The state is bestowed with two important monsoons which contribute rainfall to the state. They are: (1) Southwest monsoon during June to September and (2) Northeast monsoon during October to January. When all other states of India receive more rainfall during southwest monsoon, Tamil Nadu receives more rainfall only during northeast monsoon. The annual rainfall of the state was found to be $911.6 \mathrm{~mm}$. Northeast monsoon contributes 47 percentage of total annual rainfall whereas southwest monsoon contributes 35 percentage of total rainfall (Indira et al.,2013). As more than 80 percentage of the state depends on rainfall for their seasonal crop production, it is more prone to agricultural drought whenever monsoon fails. There are about 32 districts in the state as seen in Figure 1.

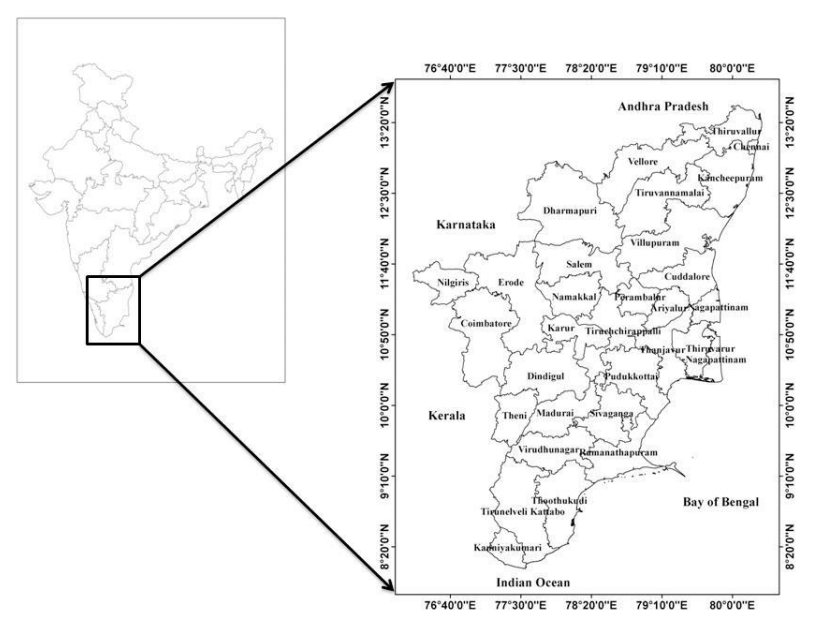

Figure 1. Map showing the study area

The topography of Tamilnadu includes coastal plains in the eastern region and hills and uplands in the western region. More than half the area of state accounts to plain surface. The coastal districts in the east like Chennai, Cuddalore, Kanchipuram, and Nagapatnam districts, the western Nilgiris hills usually receive high annual rainfall of greater than 1500

$\mathrm{mm}$. But, despite being located at the foot of the Nilgiri hills, Coimbatore district on the west receives less rainfall of around $1000 \mathrm{~mm}$. The interior districts also receive relatively less range of rainfall from 1000 to $2500 \mathrm{~mm}$.

As per 1991 census, Tamil Nadu had a population of 55.9 million. There was a huge raise in population which accounts to 62.1 million in 2001. So, it is the sixth most populous State in the country. Tamil Nadu also stands to be the densely populated state of the country. Compared to national average population density of 325 persons per sq. km, Tamil Nadu's population density is 478 persons per sq. $\mathrm{km}$. Among the major states of India, Tamilnadu is the sixth highest in population density.

Rice is the dominant food crop in Tamil Nadu and constitutes to 85.2 percentage of the total food-grains production. The other major crops that are sown here are ragi, coconut, cotton, bajra, pulses, sugarcane, maize, tea, coffee, etc. The seasonal crops are classified based on the two important monsoon seasons. Crops sown during southwest monsoon season are called Kharif crops and crops during northeast monsoon are Rabi crops. There are also perennial crops which are sown throughout the year. The ultimate source of water for all purposes in the state is only seasonal rainfall.

With the rising trend of population, risk of monsoon failure, reduction in crop production, it's very impulsive to assure food and water security in the state for future. In order to develop various strategies for improving the agricultural productivity in the state, the routine monitoring of drought level in the state becomes very important. 


\section{MATERIALS AND METHODOLOGY}

The derived composites of NDVI from Advanced Very High Resolution Radiometer (AVHRR) for every fortnight released by Global Inventory Modeling and Mapping Studies (GIMMS) (Fensholt et al.,2012) has been used in this study to calculate the VCI for a period of 20 years from 1984 to 2003. The GIMMS NDVI data are originally available at a spatial resolution of $8 \mathrm{~km}$ with the values of raw data range between -10000 to 10000 . Since the major crop growing period for the state of Tamil Nadu is from June to September, the data for those months has been considered in the present study. In every year, there are eight NDVI datasets for four months (June-September) as two fortnight datasets per month (15 day composites). They were used for VCI calculation. First, to get NDVI values in the range of -1 to +1 , a scale factor of 0.0001 was applied to the raw NDVI data i.e., the raw NDVI values were multiplied by 0.0001 to obtain the desired range of NDVI values from -1 to +1 . The raw data was in Albers Equal Area Projection. So, it has been converted to Universal Transverse Mercator (UTM) projection. Tamil Nadu state and district boundary maps prepared using Survey of India topographic maps were then overlaid. As the original GIMMS NDVI data covers the entire world, the clip option in ArcGIS 10.2 software was used to clip NDVI within the state of Tamil Nadu. As NDVI values fall below 0.1 represent areas other than vegetation, they were then removed. The raster calculator in ArcGIS 10.2 enables the computation of VCI from NDVI using the following formula.

$$
V C I=\frac{\left(N D V I_{i}-N D V I_{\min }\right)}{\left(N D V I_{\max }-N D V I_{\text {min }}\right)} \times 100
$$

In the above equation 2, NDVI $I_{i}$ indicates the NDVI of a given pixel in the raster image of one fortnight (eg. NDVI image of first fortnight of July, i.e., July 1-15 image of 1984). Whereas $N D V I_{\min }$ and $N D V I_{\max }$ indicates the minimum and maximum values of NDVI for the same pixel calculated based on all raster images of the same fortnight from 1984 to 2003. The obtained VCI values range from 0 to 100 . Those obtained raster images of VCI were then classified based on the drought severity classification proposed by (Kogan et al.,1995) as shown below in Table 1.

\begin{tabular}{|c|c|c|}
\hline $\begin{array}{c}\text { S. } \\
\text { No }\end{array}$ & VCI & $\begin{array}{c}\text { Drought } \\
\text { category }\end{array}$ \\
\hline 1 & $\geq 50$ & Normal \\
\hline 2 & $\begin{array}{c}\geq 35 \text { but } \\
<50\end{array}$ & Moderate \\
\hline 3 & $<35$ & Severe \\
\hline
\end{tabular}

Table 1 VCI classification for agricultural drought Monitoring

This particular method of finding the impact of meteorological drought on vegetation cover was found to be the best for monitoring or assessment of onset and progress of drought due to some of the criterions like the availability of free of charge data and its simplicity, more literature and minimum requirement of input data.

\section{RESULTS AND DISCUSSION}

The VCI based agricultural drought intensity maps from 1984 to 2003 are shown in Figure 2, 3, 4, 5, 6, 7, 8 and 9 for June $1^{\text {st }}$ fortnight, June $2^{\text {nd }}$ fortnight, July $1^{\text {st }}$ fortnight, July $2^{\text {nu }}$ fortnight, August $1^{\text {st }}$ fortnight, August $2^{\text {nd }}$ fortnight, September $1^{\text {st }}$ fortnight and September $2^{\text {nd }}$ fortnight, respectively.

As reported in (Nathan et al.,1995), the last decades of $20^{\text {th }}$ century faced worst droughts in Tamil Nadu. It was mentioned during the years of 1980, 1982, 1983, 1987 and 1989. As the drought analysis period of the present study in the state starts from 1984 onwards, the check on the severity of the drought during the drought affected years of 1980, 1982 and 1983 was not made possible. Anyhow, the drought during the year 1987 could be clearly observed in Figure 2 as the whole state faced a severe drought situation with many districts shown in red colour. The Similar conditions were observed in 1989 also as many districts come under severe drought category as seen in Figure 2.

During southwest monsoon period in Tamilnadu, the drought intensity levels are not during all the months as it could be well perceived through the drought intensity maps of June, July, August and September. It could be conceived that there are definite changes in the onset of monsoon during the analysis period as the vegetation status of the state as a whole was not uniform in every fortnight. During the year 1997, the whole state was under normal conditions except few districts in the first fortnight of June. But in the months of July, August and September, it went to moderate to severe condition. This shows that the early onset of monsoon which leads to failure of crops with the wrong anticipation.

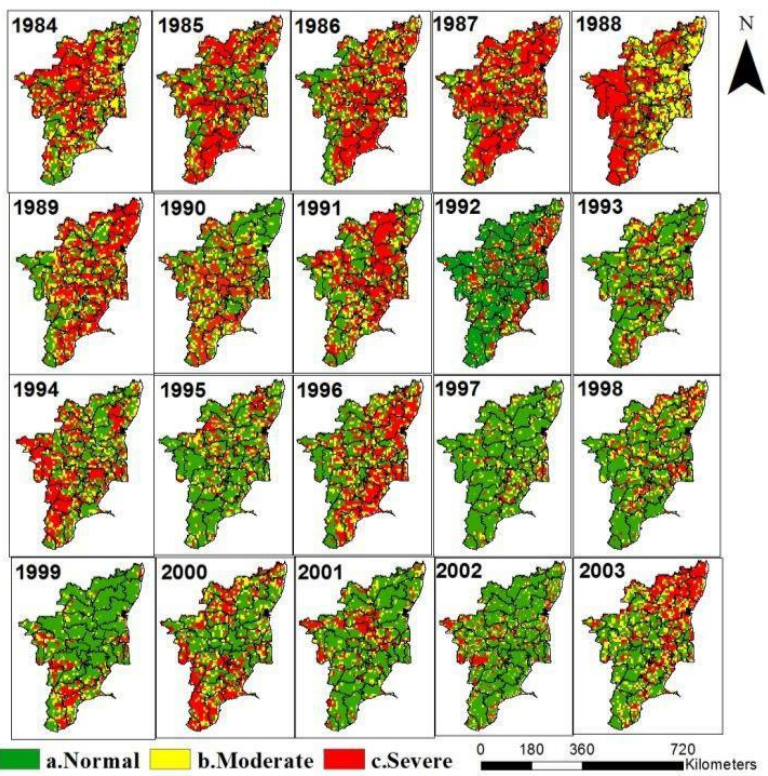

Figure 2 Drought intensity maps for 20 years during June 1st fortnight 
Drought Severity Map during second fortnight of June (1984-2003)

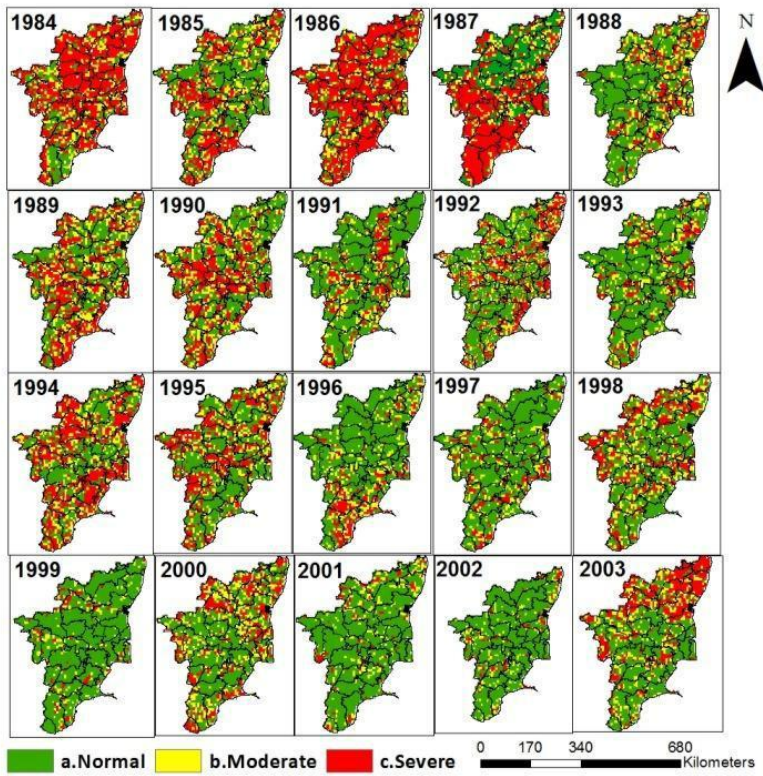

Figure 3 Drought intensity maps for 20 years during June 2nd fortnight

As kuruvai crops (short term crops which are mainly paddy) were sown and cultivated in Kharif season, the seeds are sown in the months of May to June depending on the onset of monsoon and harvested in August, September in Tamil Nadu. From Figure 2, it is noted that the green/normal condition prevailed in 1997 during the sowing time,. But because of acute shortage in rainfall, the vegetation lost its health and thus the onset of drought is witnessed in Figure 3, 4 and $5,6,7,8$ and 9 with the progression of moderate to severe condition in most of the districts during 1997.

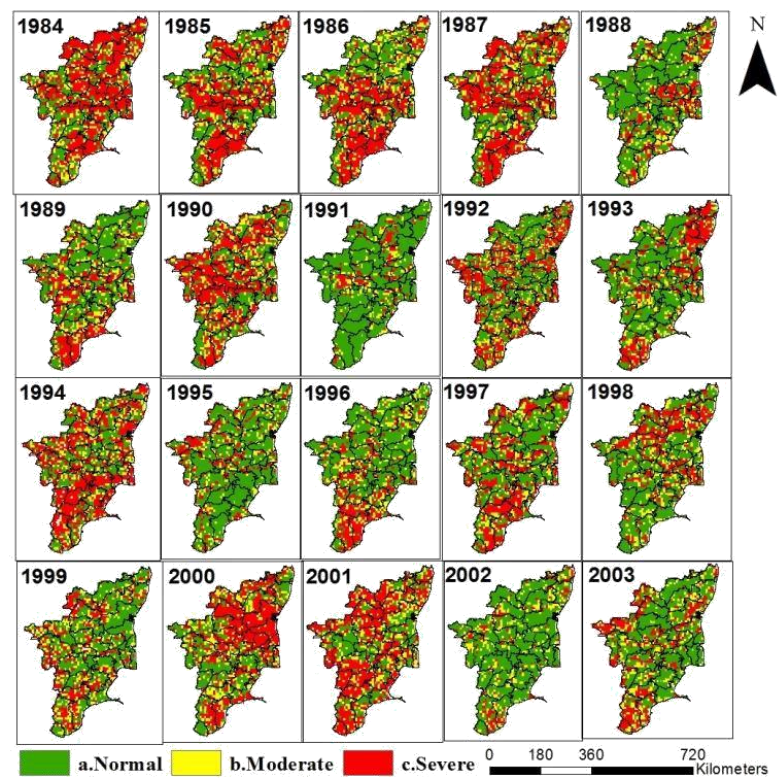

Figure 4 Drought intensity maps for 20 years during July 1 st fortnight
Drought Severity Map during second fortnight of July (1984-2003)

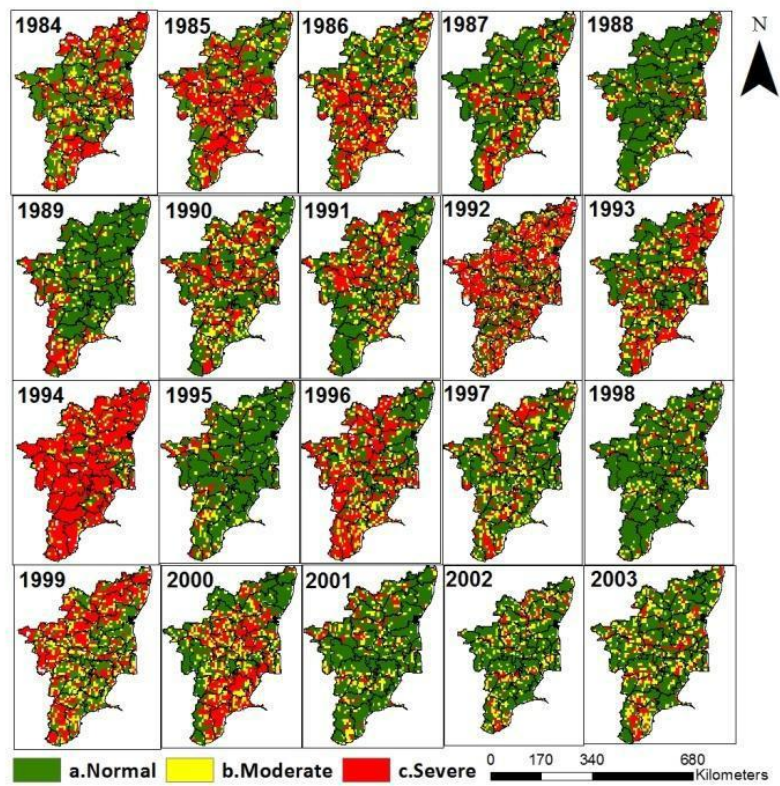

Figure 5 Drought intensity maps for 20 years during July 2nd fortnight

A keen observation of the drought intensity maps reveal that none of the districts in the state were showing normal conditions in all the year. So, the state is proved to be highly vulnerable to drought in every year mainly during the crop growing period of June, July, August and September. The early onset of monsoon and delayed monsoon both are proved to be undesirable as the fluctuations in the trend could not be ascertained.

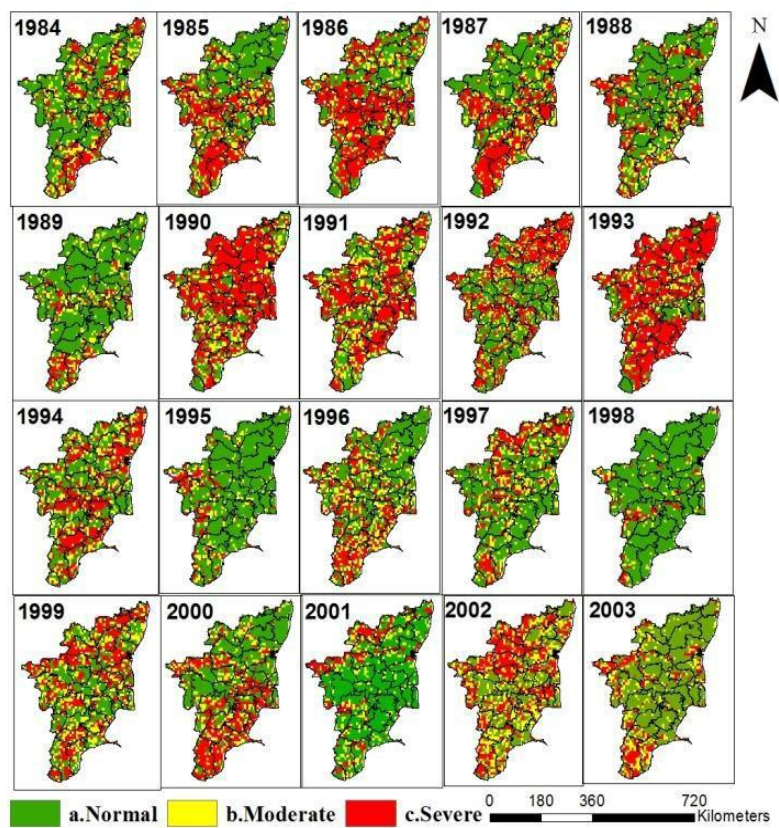

Figure 6 Drought intensity maps for 20 years during August 1 st fortnight 


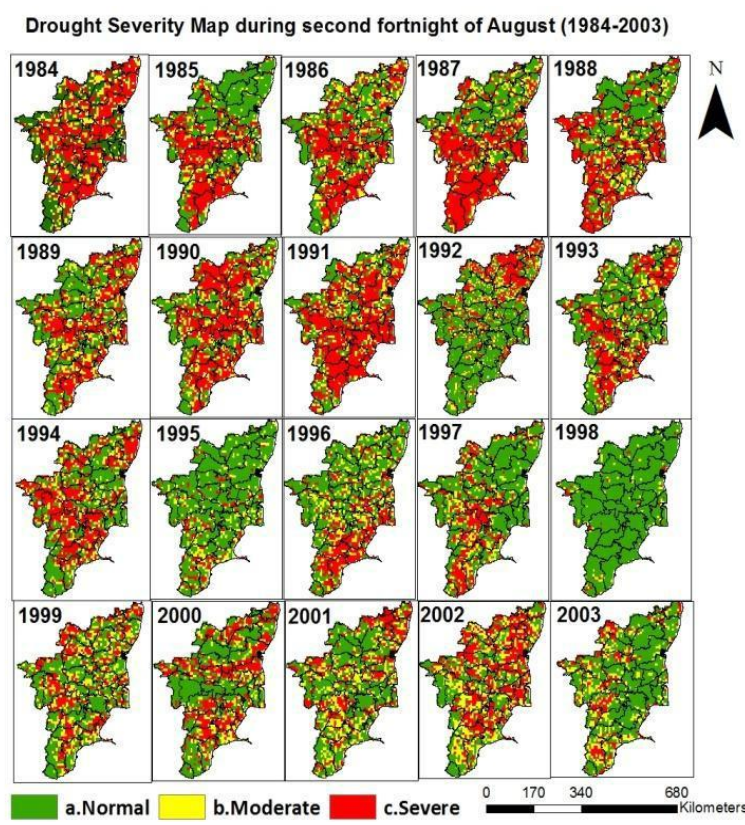

Figure 7 Drought intensity maps for 20 years during August 2nd fortnight

The flow of drought severity level from the resulting images confirms the uncertainty conditions of monsoon and poor vegetation status throughout the state in all the years. So, the release of emergency fund to the affected community after the crisis period will not be a permanent solution to guarantee the sustainability of nation. Government has to take essential steps to spot the reasons for the recurrent nature of drought in the state and take defensive measures to avoid drought in future. Strengthening of the irrigation tank bunds, performing desilting works, construction of percolation ponds, recharge structures, etc. are some of the actions that government can consider for increasing the ground water level which will in turn increase the agricultural productivi

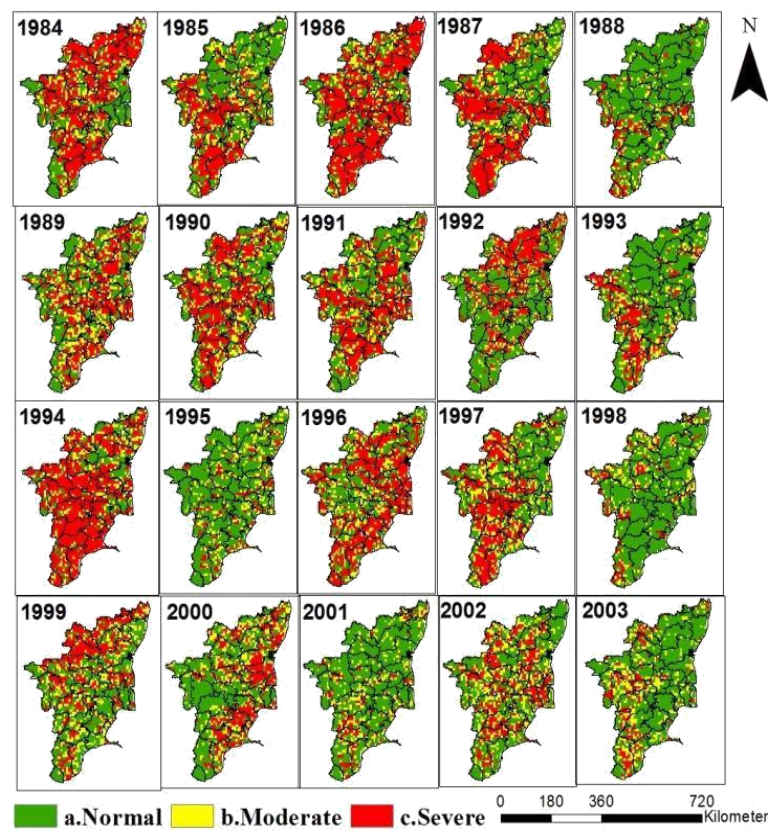

Drought Severity Map during second fortnight of September (1984-2003)

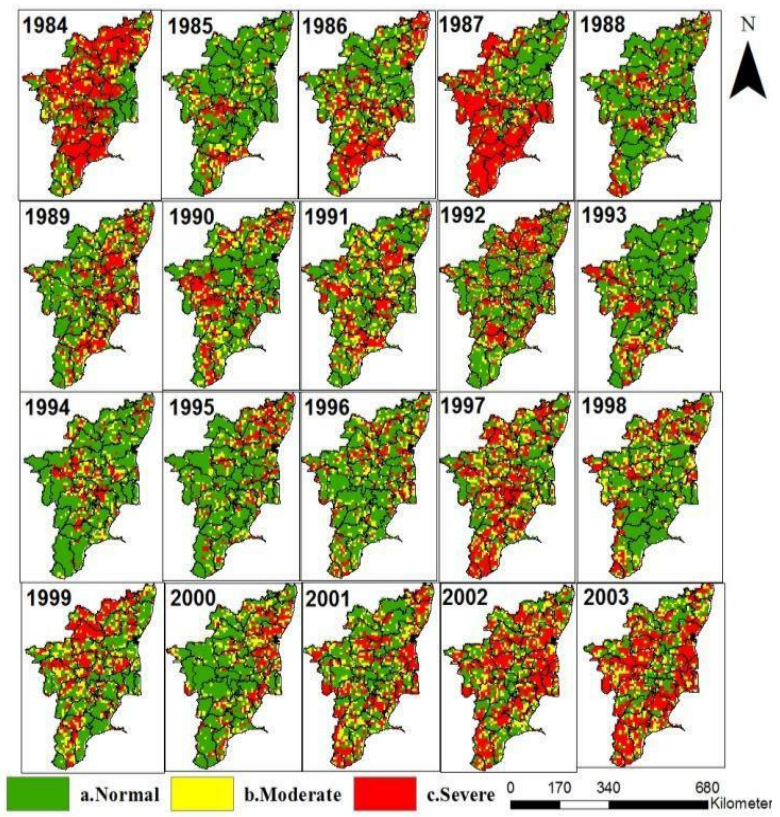

Figure 9 Drought intensity maps for 20 years during September $2^{\text {nd }}$ fortnight

\section{CONCLUSION}

The sole dependency on rainfall for agriculture in India is one of the major reasons to witness drought even during the minor deviation of rainfall from the normal. The impacts are ultimately largely observed in the agricultural production. The recent statistics says that large number of farmers commit suicides because of crop failure. The social and economical welfare of any nation depends on how well the nation could manage the crisis situations without compromising their development.

This is the main reason why developing nations are still be in the same state or even worse over many years. For developing countries like India, whose economy and social status largely depends on agricultural sector, it's the foremost need to improve the agricultural productivity by the acts of preparedness during failure of monsoon. The present study was attempted in the way to study and monitor the drought level of Tamil Nadu using the popular index called VCI. The prepared drought intensity maps for the state of Tamilnadu for a period of 20 years using NDVI based VCI and the very efficient spatial data management tool Geographical Information System (GIS). . The results showed that the state is experiencing moderate to severe drought situation during the analysis period of 20 years. The fortnightly variation of drought also alarms the government to take suitable preventive measures to avoid drought in future. For better management of drought, Soil and water conservation measures like construction of contour bunds, check dams, percolation ponds, etc. should also be considered by the government.

Figure 8 Drought intensity maps for 20 years during September 1st fortnight 


\section{ACKNOWLEDGEMENT}

The authors would like to acknowledge Vellore Institute of Technology (VIT) management for their constant support and motivation towards pursuing this research work.

\section{REFERENCES}

Anyamba, A., Tucker, C.J., and Eastman, J.R., 2001, NDVI anomaly patterns over Africa during the 1997/98 ENSO warm event, Int. J. Remote Sens, 22, pp.1847-1859.

Domenikiotis, C., Spiliotopoulos, M., Tsiros, E., and Dalezios, N.R., 2004, Early cotton yield assessment by the use of the NOAA/AVHRR derived drought Vegetation Condition Index in Greece, Int. J.Remote Sens., 25, pp.28072819.

Dutta, D., Kundu, A., and Patel, N.R., 2013, Predicting agricultural drought in eastern Rajasthan of India using NDVI and Standardized Precipitation Index (SPI), Geocarto International. 28(3), pp.192-209.

Dutta, D., Kundu, A., Patel, N.R., Saha S.K., and Siddiqui, A.R., 2015, Assessment of agricultural drought in Rajasthan (India) using remote sensing derived Vegetation Condition Index (VCI) and Standardized Precipitation Index (SPI), The Egyptian Journal of Remote Sensing and Space Sciences, 18, pp.53-63.

Fensholt, R., and Proud, S.R., 2012, Evaluation of earth observation based global long term vegetation trends comparing GIMMS and MODIS global NDVI time series, Remote Sens. Environ., 119, pp.131-147.

Indira, P., and Inbanathan, S., 2013, Studies on the trend and chaotic behaviour of Tamil Nadu rainfall, J. Ind. Geophys. Union., 17(4), pp.335-339.

Jain, S.K., Keshri, R., Goswami, A., and Sarkar, A., 2010, Application of meteorological and vegetation indices for evaluation of drought impact: a case study for Rajasthan, India. Nat. Hazards 54, pp.643-656.

Kogan, F.N., 1995, Application of vegetation index and brightness temperature for drought detection. Adv. Space Res. 15, pp.91-100.

Legess, G., and Suryabhagavan, K.V., 2014, Remote sensing and GIS based agricultural drought assessment in East Shewa Zone, Ethiopia, Tropical Ecology, 55(3), pp.349-363.

Liang, L., Qin Sun., Xiang, L., Jiahui,W., Lianpeng,Z.,Meixia.,D., Liping,D., and Zhixiao,L., 2017, Long term spatial and temporal variations of vegetative drought based on vegetation condition index in China, Ecosphere,8(8):e01919.10.1002/ecs2.1919

Liu, W.T., and Kogan, F.N., 1996, Monitoring regional drought using the Vegetation Condition Index (VCI), International Journal of Remote sensing, 17(14), pp.27612782.

Nathan, K.K., Assessment of Recent Droughts in TamilNadu, Drought Network News, The National
Drought Mitigation Center, University of Nebraska-Lincoln, (October 1995)

Quiring, S.M., and Ganseh, S., 2010, Evaluating the utility of the Vegetation Condition Index

(VCI) for monitoring meteorological drought in Texas. Agric. For. Meteorol., 150, pp.330-339.

Revised August 2018 